\title{
Peer tutors' views on their role in motivating learners to learn mathematics
}

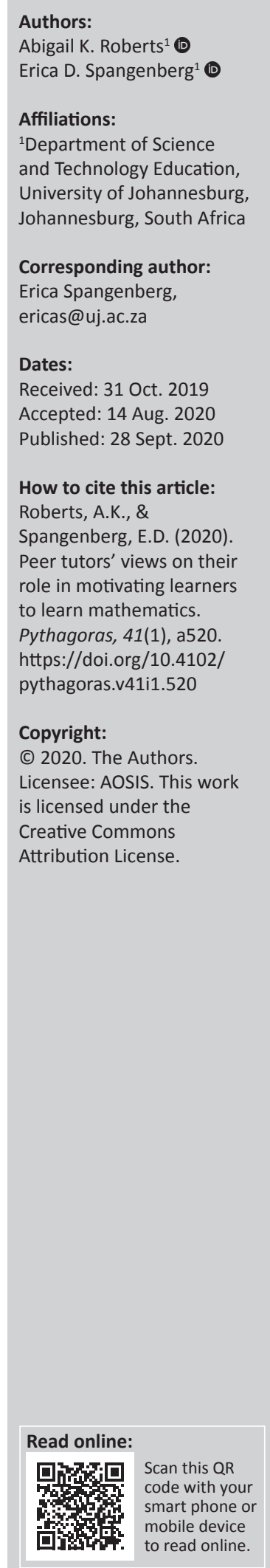

Many learners are unmotivated to learn mathematics due to a lack of attention, irrelevance of mathematics, low self-confidence and dissatisfaction. However, peer tutoring can afford learners opportunities to engage with other individuals who have overcome similar challenges in the learning of mathematics and who can motivate them to become increasingly mindful of the task at hand at their own pace in a one-on-one relationship. This article reports on Grade 12 peer tutors' views on their role in motivating Grade 8 and Grade 9 learners to learn mathematics in relation to the four categories of learner motivation, namely attention, relevance, confidence and satisfaction (ARCS). The four categories adapted from the ARCS model of motivation were used as a lens to view and analyse the data using theoretical thematic analysis. This qualitative article utilised pre- and post-interviews as data collection instruments. Ten of the best-performing Grade 12 learners at an ex-model C school in Gauteng province in South Africa were purposively selected to participate in the research. The findings revealed that peer tutors view their role to motivate learners to learn mathematics peculiar to seven positions, which can inform future research on intervention strategies to improve mathematics performance. This article introduces research on an adapted use of the ARCS model of motivation in motivating learners to learn mathematics, which is a novel way of bringing new perspectives to research on motivation in mathematics at secondary school level.

Keywords: Mathematics; motivation; peer tutor; learning; secondary school.

\section{Introduction and background}

In South Africa, mathematics performance for Grade 5 and Grade 9 evident from the Trends in International Mathematics and Science Study (TIMSS) reports is consistently poor in comparison with other developing countries such as Botswana, Indonesia, Turkey and Malaysia (Mullis, Martin, Foy, \& Hooper, 2016). According to the 2015-2016's World Economic Forum Global Competitiveness report, South Africa's mathematics performance is among the lowest of 140 countries (Schwab, 2015). Mathematics performance is a proxy of a learner's ability to achieve academically (Huang, Craig, Xie, Graesser, \& Hu, 2016) and affects how the world views a country's ability to perform internationally (Bartelet, Ghysels, Groot, Haelermans, \& Maassen Van den Brink, 2016).

A key factor influencing learners' mathematics performance is motivation (Karakis, Karamete, \& Okcu, 2016). Ample research has shown that motivation is a necessary aspect of mathematics performance (Cleary, Velardi, \& Schnaidman, 2017; Wilkins \& Ma, 2003; Winberg, Hellgren, \& Palm, 2014). Learners who perform well often have high levels of motivation to achieve and therefore they put much effort into their learning (Kim, Park, Cozart, \& Lee, 2015). When individuals are motivated their anxiety level decreases and their confidence increases (Arroyo et al., 2014). Motivated learners are also more focused and perform better in mathematics since they are more likely to persevere even when mathematics concepts are challenging (Arroyo et al., 2014). Therefore, it is essential to ensure that learners are motivated to learn mathematics and that they stay motivated (Schukajlow, Rakoczy, \& Pekrun, 2017).

The concept of motivation is complex and various disciplines have taken many years to attempt to understand what motivation entails (Güvendir, 2016). The Oxford Dictionary of English Grammar (2010) (https://www.oxfordlearnersdictionaries.com/definition/english/) defines motivation as 'a reason, desire, willingness or enthusiasm ... for acting or behaving in a particular way' (p. 963). Rheinberg and Engeser (2018) stated that motivation could be defined as the moment when individuals direct their life's actions towards a positive goal. However, Heckhausen (2018) claimed that motivation is more than the desire that controls an individual's actions. Specifically, motivation is learners' natural yearnings and inclinations that influence 
how they act (Heckhausen, 2018). Ryan and Deci (2000) also acknowledged that motivation is involved in causing learners to act and that learners' motivation is often related to the communities that they find themselves in. For this article, the authors argue that motivation is the desire that learners have to learn mathematics, which can either be intrinsic, realised by themselves, or extrinsic, reached by teachers with the support of peer tutors who understand their role in motivating learners to learn mathematics.

In the context of this study, the mathematics department at the school, the site of the current article, was also concerned about decline in mathematics performance of Grade 8 and Grade 9 learners over the past few years. This low mathematics performance could be linked to learners' dependency on the teacher (Heyd-Metzuyanim \& Graven, 2016) and, specifically, their levels of motivation (Karakis et al. 2016). Although the mathematics teachers provided extra mathematics lessons twice a week after school hours, learners' mathematics performance did not improve noticeably. In addition, many learners were unmotivated to attend the extra mathematics lessons due to inconvenient times, intimidation from other learners and aversion to the structured environment. Peer tutoring as an intervention was suggested to address these challenges as learners might experience less intimidation when approaching fellow learners, and the daily contact in an unstructured environment could motivate them to focus on their mathematics learning. Heyd-Metzuyanim and Graven (2016) acknowledged that a strategy to address poor mathematics performance is peer tutoring, which has the potential to increase learners' motivation.

One of the authors, in her capacity as a teacher in a high school, has observed that many learners are unmotivated to learn mathematics due to various reasons. Some learners find it challenging to pay attention in the mathematics classroom, or view mathematics as not useful. Others do not have confidence in their abilities to engage in mathematics, or could be unsatisfied with the quality of feedback received from teachers. Peer tutors could assist teachers and learners in addressing these aspects if they comprehend their role in motivating learners to learn mathematics.

Several reasons could contribute to learners finding it challenging to pay attention in the mathematics classroom. Many mathematics classrooms in South Africa are crowded. According to Ntow and Adler (2019), such classrooms have a propensity for teachers to dominate discussions, while learners have limited chances to communicate openly or with other learners. However, peer tutors, either in the same grade level, or in the case of this study in a higher grade level, can provide learners who are struggling with mathematics with one-onone attention that is not always possible in a crowded classroom. In addition, when learners are involved in a task, they have greater awareness of the content being taught. By engaging with peer tutors, learners could be encouraged to become increasingly mindful of the task and in return are often more motivated to continue with the task (Kim et al., 2015).
According to Hernandez-Martinez and Vos (2018), the usefulness of mathematics provides relevance to mathematics. However, from the authors' perceptions, many learners are demotivated and view mathematics as irrelevant and not applicable in real life or for their future endeavours. However, when peer tutors demonstrate the future relevance of what the learner could achieve, they may enable the learner to envision what the future may hold, which could motivate learners to learn mathematics. According to Keller's (1987) ARCS model of motivation, relevance ensures that learning fulfils the requirements for future study (Izmirli \& Izmirli, 2015; Milman \& Wessmiller, 2016).

The authors argue that learners' sense of themselves directly affects their motivation to achieve in mathematics. Learners with a positive mathematics identity view mathematics as enjoyable and worthwhile and are confident in their ability to learn the subject and strive to become possible selves. According to Oyserman, Destin and Novin (2015), possible selves refer to people's aspirations and challenges for the future to form their identity. Thus, positive selves in this study signify learners' motivation and identity; thus, what learners envision themselves to become, what they desire to become, as well as their anxieties of who they do not want to become play into incentive and motive. Focusing on the elements of identity, namely ideal self, ought self and learning experiences, learners are motivated to become the possible selves they have envisioned. Oyserman et al. (2015) claimed that both the ideal self and ought self are desired identities a person wishes or feels compelled to become. The ideal self refers to what an individual would like to become, and the ought self refers to the characteristics that individuals believe they should have. Learning experiences refer to the context where learning takes place such as the mathematics classroom. According to Oyserman et al., learning contexts affect which identities transpire, the consequences of these identities for learning, and how learning difficulties are probably accounted for. Perceptions of mathematics being difficult or a virtue one is born with could have a negative influence on learners' selfconfidence to engage in mathematics. Peer tutors could be able to address learners' beliefs about themselves and the mathematics to be acquired and assist learners with the mathematics content to be learnt.

According to Kim et al. (2015), learners tend to be more motivated if they perceive the importance of a task. Therefore, the authors argue that when learners believe that they are prepared for mathematics tasks, learners' motivation increases. However, mathematics tasks should not be too challenging for learners. When a task is perceived as too difficult, learners can be led to believe that they are failures, and this negatively influences their motivation. Therefore, Schukajlow et al. (2017) argued for more attention to the content in mathematics tasks as motivation is contentspecific.

Satisfaction is linked to feedback (Milman \& Wessmiller, 2016) and forms part of extrinsic motivation (Güvendir, 2016). 
Extrinsic motivation refers to the achievement of a goal to accomplish another goal such as praise or the avoidance of punishment for example negative feedback (Güvendir, 2016). Intrinsic motivation, conversely, is the innate longing of learners to achieve a desired outcome or simply complete a task for pure pleasure without seeking for a reward (Winberg et al., 2014). During contact time, teachers often need to continue with new mathematics content to complete the mathematics syllabus and cannot immediately provide feedback to learners' queries. Neglecting learning difficulties in mathematics could negatively influence learners' extrinsic motivation to learn the subject. Assistance by peer tutors, however, may enhance the response time for feedback and enable learners to gain satisfaction for and from their work (Izmirli \& Izmirli, 2015). Learners would not have to wait for a formal lesson by their teachers, but could be assisted by peer tutors to build understanding of the subject content (Karakis et al., 2016) at their own pace and in their own time (Kroeger \& Kouche, 2006). The involvement of peer tutors in the learning process can enhance learners' motivation and eventually lead to better mathematics performance (Kim et al., 2015).

Despite the benefits peer tutors can add to the learning of mathematics, Kim et al. (2015) acknowledged that there is a need for an inquiry on how peer tutors perceive their role in motivating other learners to participate in the mathematics classroom. The authors believe that peer tutors' views regarding their role in motivating learners matter, because their views will determine how they will motivate other learners to participate in the mathematics classroom.

Many international studies on motivation in mathematics have been conducted (Chue \& Nie, 2017; Goldin et al., 2016; Novak, 2014; Schukajlow et al., 2017; Winberg et al., 2014; Yu \& Singh, 2018). Among them, Novak (2014) discussed the need for learners to have learning that learners believe to be applicable to their real-life experiences and that will be appealing to them. Schukajlow et al. (2017) focused their research on affective constructs such as emotions and motivation, and how these constructs influence learners' views and interest in mathematics. Winberg et al. (2014) found that learners' emotional experience of mathematics affects their motivation. If learners perceive the content to be interesting or useful, they are more likely to engage with it.

Ample research has also been dedicated to motivation in mathematics at school level in South Africa (George \& Adu, 2018; Grobler, Moloi, \& Thakhordas, 2017; Oswald \& Rabie, 2016; Tsanwani, Harding, \& Engelbrect, 2014). In particular, Grobler et al. (2017) discussed the need to increase mathematics teachers' self-motivation. Oswald and Rabie (2016) found that gifted learners who are motivated and persistent are more likely to achieve in mathematics. However, none of the aforementioned studies relates the role that motivation plays in the learning of mathematics to peer tutoring as an intervention strategy.

\section{Purpose of the study}

This article reports on a study (Roberts, 2019) with the purpose of establishing the views peer tutors hold with regard to their role in motivating Grade 8 and Grade 9 learners to learn mathematics in relation to the four categories of learner motivation, namely attention, relevance, confidence and satisfaction, adapted from Keller (1987).

\section{Peer tutoring as an intervention strategy}

Motivation to achieve is often driven by a desire to be included and to be a part of something (Kim et al., 2015) - for example, being included or accepted in a learning community consisting of participants who contribute to meaningful mathematics discussions and support in the teaching and learning of mathematics such as peers, tutors and teachers. The learning community and the views of learners as part of that community play an integral role in learners' motivation (Gardner, 1985), particularly in mathematics (Lutovac \& Kaasila, 2014). Peer tutoring is a strategy to create such a community that could address learners' beliefs about themselves and the mathematics they need to acquire (Hoops, Yu, Wang, \& Hollyer 2016). A community of learning could also motivate peer tutors in their perceptions of their role to learn new mathematics content and to accept their limitations pertaining to their own subject content (Galbraith \& Winterbottom, 2011).

With class sizes increasing at colleges and universities globally, tutoring and more specifically peer tutoring has grown in popularity (Alegre, Moliner, Maroto, \& LorenzoValentin, 2020; Nawaz \& Rehman, 2017). In South Africa, tutoring has increased significantly since the 1990s (Clarence, 2018). Tutoring in South Africa is an important intervention strategy that is utilised mainly at university level as an essential mediation that affects learners' ability to retain the knowledge that they have acquired (Layton \& McKenna, 2016). The tutorial system enables students an opportunity to gain the necessary knowledge to pass (Clarence, 2018; Layton \& McKenna, 2016). However, peer tutoring is not a common formalised intervention strategy used at the school level. The meta-analysis on peer tutoring in secondary education conducted by Alegre, Moliner, Maroto and Lorenzo-Valentin (2019) also revealed that implications for practice at the secondary education level have not been investigated sufficiently despite ample existing literature on peer tutoring in mathematics at higher education level.

Peer tutoring in mathematics can be linked to increased academic performance. By affording learners the opportunity to engage with other individuals, learners can become increasingly mindful of the mathematics task and are often more motivated to continue with the task at hand (Gardner, 1985; Kim et al., 2015). Peer tutors either can address motivation explicitly or, depending on the availability and access to individualised assistance, can implicitly inspire learners' motivation to achieve in mathematics (Grills, 2017). 
Research on peer tutoring has indicated several benefits. Peer tutoring could possibly shorten the response time for feedback from the teacher or allow learners the opportunity to linger over sections of work at their own pace, in their own time, after the teacher has moved on to new work (Kroeger \& Kouche, 2006). This feedback enables learners to build their own understanding of the content (Karakis et al. 2016). Due to the encouragement of discourse and communication between the learner and the peer tutor, peer tutoring can address the need for peer approval (Kim et al., 2015). Peer tutoring focuses on a one-on-one relationship between the learner and peer tutor. This relationship has the potential to have a greater impact on the learner since the peer tutor and learner often have more in common (Kroeger \& Kouche, 2006).

Despite the many benefits attached to peer tutoring, a disadvantage might be the perceived status difference between peer tutors and learners, which can result in negative relationships outside the classroom (De Backer, Van Keer, \& Valcke, 2015). Although both the peer tutors and learners have a joint responsibility in regulating learning, peer tutors play a more instructive role to guide learners in their learning of mathematics, while learners have to take ownership for their own learning. This difference in roles may result in some peer tutors becoming too directive in regulating learning, while learners may view peer tutors as the ones responsible for managing their learning. Despite research showing predominately positive social interactions between peer tutors and learners (Greene, Mc Tiernan, \& Holloway, 2018), De Backer, Van Keer and Valcke (2015) suggested further research on negative socio-emotional peer interactions since there is the opportunity that they might have a negative influence on the learners.

Regrettably, much research related to affective constructs in peer tutoring focuses on learners and not on peer tutors. Kroeger and Kouche (2006) revealed that peer tutoring at an inclusive middle school in the Midwest (United States) affects learners' attitudes towards mathematics positively. In addition, Topping, Cambell, Douglas and Smith (2003) discovered at a rural primary school in the United Kingdom that mathematics games in peer tutoring have a positive impact on the attitudes of learners towards mathematics and encourage learners to continue with mathematics even when they find the content difficult. Therefore, Kim et al. (2015) argued for the need of an inquiry on how peer tutors perceive their role in motivating learners to engage in the mathematics classroom.

\section{An overview on the ARCS model of motivation in and adapted sense}

Keller (1987) developed the ARCS model of motivation in response to a need for an ordered and more logical way of recognising and solving problems in learners' motivation. This model endeavours to stimulate and encourage learners' desire to achieve (Karakis et al., 2016), and an adaptive
ARCS model provides thus an effective framework for understanding peer tutors' views on their role in motivating learners to learn mathematics. Keller's ARCS model of motivation focuses on four aspects of a learner's motivation, namely Attention, Relevance, Confidence and Satisfaction (Keller, 1987). This model is designed to create healthy learning environments while ensuring that learners' motivation is addressed (Izmirli \& Izmirli, 2015; Karakis et al., 2016).

The first category of Keller's (1987) ARCS model of motivation, Attention, aims to gain the learners' attention by introducing different teaching methods and presentation (Izmirli \& Izmirli, 2015). Attention involves (1) capturing learners' interest, (2) stimulating their inquiry and (3) maintaining their attention (Keller, 2000). A strategy to capture interest includes the introduction of seemingly contradicting facts or experiences that the learner previously thought were true, known as the incongruity or the conflict aspect. Another strategy is to provide different and varied ways of presenting mathematics content, such as using computer programs, videos or group activities to keep learners motivated (Novak, 2014). Demonstrating mathematics to the learners through visual examples or models - concrete representations - also aids in keeping learners interested in the subject. Likewise, variation or humour may change the way the content is presented and can stimulate learners' interest (Keller, 1987).

Relevance is the second category of Keller's (1987) ARCS model of motivation and one that ensures learning fulfils the requirements for future study or a chosen career (Izmirli \& Izmirli, 2015; Milman \& Wessmiller, 2016). The instructor, whether a teacher or a tutor, links content to familiar events or current happenings (Milman \& Wessmiller, 2016) by (1) relating it to goals, (2) matching it with learners' interests or (3) connecting it to learners' experiences. It is useful for the learner to be able to link learning, where possible, to multiple situations. Teachers should also link mathematics lessons to their future usefulness (Izmirli \& Izmirli, 2015). Some strategies could include (1) relating the mathematics curriculum to real-world issues, (2) addressing learners' educational needs, (3) linking present content to future needs, (4) clearly laying out objectives, (5) encouraging group work and (6) addressing learners one on one (Milman \& Wessmiller, 2016). Showing the relevance of mathematics increases motivation because learners are able to see how mathematics content links to other subjects and it develops a greater understanding of why mathematics learning is necessary for them.

Thirdly, Keller's (1987) ARCS model addresses the category of Confidence. Learners need to believe that they are capable of completing tasks. Confidence includes how secure the learners feels in their learning environment (Keller, 1987) and includes their success expectations. When learners believe that they can achieve, their chances of successfully completing a task are increased (Keller, 1987); thus their success opportunities increase. Learners' confidence plays a vital role 
in their perseverance and achievement (Keller, 1987). When learners feel confident to begin - and possibly complete - a task, thus taking personal responsibility, their self-efficacy is addressed (Hodges \& Kim, 2013). Focusing on what learners are able to do enhances confidence in learners. Allowing learners to apply work and display what they have done affords them the chance of feeling good about their work (Milman \& Wessmiller, 2016).

Satisfaction focuses on how learners feel about tasks they have accomplished. Personal satisfaction refers to the pride a learner feels when a task is completed (Izmirli \& Izmirli, 2015; Keller, 2000). Although intrinsic motivation is important, it can be difficult to impact and develop. Intrinsic satisfaction occurs (1) when learners receive credit for their achievements (Keller, 2000) that matches their intrinsic feeling about their accomplishments and (2) when learners feel that others have acted fairly towards them (Keller, 2000). It is important that learners feel that they have been treated fairly, that the workload was reasonable and consistent and that there was no discrimination (Keller, 2000). External motivation, through awards or praise, is easier to influence. Extrinsic rewards can be either functional or representative like the receiving of recognition in practical and tangible methods such as marks, honours and other visible recognitions of achievement (Keller, 2000). Deriving from research studies, the authors do not view intrinsic or extrinsic motivation as better than the other. If learners are positively motivated and mathematics learning takes place, the type of motivation teachers provide or what learners prefer is of less concern.

\section{Research question}

The research question is: What are Grade 12 peer tutors' views on their role in motivating Grade 8 and Grade 9 learners in learning mathematics in relation to the four categories of learner motivation adapted from Keller (1987)?

\section{Research methodology}

A predominantly qualitative research method was used to establish peer tutors' views on their role as motivators in the learning of mathematics. This method was suitable as it was used for an exploratory purpose to seek deeper understanding of a real-life event in a context-specific setting (Creswell, 2013). The four categories adapted from Keller's (1987) ARCS model of motivation were used as a lens in designing the interview schedule, as well as in analysing the data using theoretical thematic analysis (Braun \& Clarke, 2006). Although qualitative data were collected, the data were also quantified to generate a deeper insight into the relevance of the codes in terms of frequency, and to minimise subjective inferences (Keller, 2017).

The study was conducted in an ex-Model C school in the north of Johannesburg. Ex-Model C schools are semi-private institutions in South Africa receiving government funding for some staff salaries, but parents are also charged fees.
These schools used to be for white children only during the apartheid era before 1991, but are now multicultural and highly diverse. The school had approximately 300 learners in Grade 8 and 300 learners in Grade 9. From a population of 15 Grade 12 peer tutors at the school, 10 peer tutors were purposively selected based on the following criteria: (1) voluntarily participation, (2) attending a school with an existing peer-tutoring programme, (3) in Grade 12, (4) selected mathematics as a subject and (5) obtained an average greater than $80 \%$ in Grade 11 . There were six female and four male participants.

The peer-tutoring programme ran for nine months (February to October) from Monday to Thursday for an hour and a half after school. Learners in need of additional support in mathematics could only be identified by the end of January after availability of the first cycle test results. The programme was concluded by the end of October before the final Grade 12 examinations. The programme was conducted after school hours to ensure that it did not affect contact time during normal school hours, but also to allow sufficient time to support learners. There were two to three peer tutors assisting the learners on each day. Learners who had received low marks for a test or a previous examination were encouraged by their teachers and the head of the mathematics department to attend in order for them to gain extra practice and assistance.

One-on-one, semi-structured interviews with the 10 peer tutors were conducted at the beginning and the end of the nine months that the peer-tutoring programme ran. Similar interview questions were utilised for both periods. The interview questions were conceptualised in relation to the research question (What are Grade 12 peer tutors' views on their role in motivating Grade 8 and Grade 9 learners in learning mathematics in relation to the four categories of learner motivation (attention, relevance, confidence, satisfaction) adapted from Keller (1987)?) and the problem statement (Many learners are unmotivated to learn mathematics because they find it challenging to pay attention in the mathematics classroom, view mathematics as not useful, do not have confidence in their abilities to engage in mathematics, and could be unsatisfied with the quality of feedback received from teachers). The interview questions were:

- What do you think your role as a peer tutor in the learning of mathematics is? Elaborate.

- How would you as a peer tutor ensure that learners' attention is maintained in the learning of mathematics?

- How would you as a peer tutor ensure that learners are able to see the relevance of mathematics?

- How would you as a peer tutor ensure that learners' confidence in mathematics improves?

- How would you as a peer tutor ensure that learners feel satisfied about the mathematics they learn?

The interviews were transcribed word for word and captured, using the software package ATLAS.ti, to engage with the details of the interviews. Data were analysed 
using theoretical thematic analysis (Braun \& Clarke, 2006). Predetermined categories were used that aligned closely with the research question adapted from Keller's (1987) ARCS model of motivation, namely Attention, Relevance, Confidence and Satisfaction, as well as synonyms or similar terms, for example 'responsive', 'importance', 'comfortable' and 'pleased'. Retrieving meaning from the categories was done by sorting the categories into subcategories and further breaking the subcategories into codes.

To ensure trustworthiness, the research question guided the progress of the research and determined the choice of instrument. All data were compared against the adapted ARCS model of motivation for consistency in results. Furthermore, previous research done by Keller (1987) was used as a guide to develop the interview questions and to strengthen the dependability of this study. A dense account of the context and a detailed description of the data collection and analyses procedures contributed to this study (Rule \& John, 2011), which also set the conditions for other researchers to decide on the credibility and transferability of the study. However, the contextual nature of this study only allows for transferability if adapted to a similar context. Nevertheless, the authors supplied a thorough literature review from previous studies, conducted in and outside of South Africa, for further reference. To ensure confirmability, member checking was done with the participants by verifying, and amending where needed, the correctness of the interpretation of data collected from the interviews (Rule \& John, 2011). All claims and findings were supported by data and controlled against previous findings from literature. Faculty members at the University of Johannesburg, who are experts in the field of mathematics education, checked all interview questions to ensure that they relate to answering the main research question and to establish that the interview questions are suitable to the purpose of the study.

\section{Ethical consideration}

Finally, because one of the authors was a teacher at the school, full ethical considerations (ethical clearance number 2018-021) were adhered to in order to address researcher bias. Ethical considerations were implemented to protect the participants and the researchers. For this research study, it was important that the researchers valued the participants' privacy. University of Johannesburg Faculty of Education Research Ethics Committee NHREC registration number: REC-110613-036.

\section{Results}

Table 1 illustrates the frequency of comments made in the interviews on what peer tutors' views are on their role in motivating Grade 8 and Grade 9 learners in learning mathematics in relation to the four categories of learner motivation adapted from Keller's (1987) model, namely Attention, Relevance, Confidence and Satisfaction, as well as the number of participants who responded per code. The frequency $(f)$ and percentage of responses from the peer
TABLE 1: Categories, subcategories and codes.

\begin{tabular}{|c|c|c|c|c|}
\hline Category & $\begin{array}{l}\text { Frequency, } \\
f=107\end{array}$ & Subcategories & Codes & $n=10$ \\
\hline \multirow[t]{6}{*}{ Attention } & $57(53.3 \%)$ & Capture interest & Incongruity & 0 \\
\hline & & & Concreteness & 8 \\
\hline & & & Variation & 9 \\
\hline & & & Humour & 0 \\
\hline & & Stimulate inquiry & Inquiry & 6 \\
\hline & & Maintain attention & Participation & 6 \\
\hline \multirow[t]{6}{*}{ Relevance } & $18(16.8 \%)$ & Relate to goals & Experience & 0 \\
\hline & & & Present worth & 0 \\
\hline & & Match interests & Future usefulness & 4 \\
\hline & & & Need matching & 5 \\
\hline & & Tie to experiences & Modelling & 3 \\
\hline & & & Choice & 0 \\
\hline \multirow[t]{5}{*}{ Confidence } & $17(15.9 \%)$ & Success expectations & Learning requirements & 0 \\
\hline & & Success opportunities & Difficulty & 3 \\
\hline & & & Expectations & 1 \\
\hline & & Personal responsibility & Attributions & 7 \\
\hline & & & Self-confidence & 6 \\
\hline \multirow[t]{5}{*}{ Satisfaction } & $15(14.0 \%)$ & Intrinsic satisfaction & Natural consequences & 2 \\
\hline & & Rewarding outcomes & Unexpected rewards & 2 \\
\hline & & & Positive outcomes & 5 \\
\hline & & & Negative influences & 0 \\
\hline & & Fair treatment & Scheduling & 0 \\
\hline
\end{tabular}

Source: Adapted from Roberts, A.K. (2019). Grade 12 peer tutors' conceptions of their role as motivators for Grades 8 and 9 mathematics learners. Unpublished master's thesis, University of Johannesburg, Johannesburg

tutors that were relevant to the four categories were calculated. The number $(n)$ of peer tutors who responded to the codes was also determined.

All 10 peer tutors addressed certain aspects under the categories of Attention and Confidence. Most of the comments were made under the category on Attention (57 out of $107 ; 53.3 \%$ ), while only 17 out of 107 responses (15.9\%) referred to the category on Confidence. Seven peer tutors (18 out of 107 utterances; 16.8\%) deliberated on some aspects under the category on Relevance. Although nine peer tutors mentioned a few aspects under the category on Satisfaction, only 15 out of 107 (14.0\%) remarks were made in this regard.

\section{Attention}

Three subcategories are classified under the category on Attention, namely capturing interest, stimulating inquiry and maintaining attention (Keller, 2000), which address learners' motivation to participate in the mathematics classroom. First, nine peer tutors, thus most of the participants, referred to capturing of the learners' interest as a strategy to get their attention. Although none of the peer tutors stipulated that they used incongruity or humour as a way to get learners' attention, eight peer tutors indicated that they captured learners' interest by utilising visual representations. Participant 1 commented that 'using the white board [and using] different colours helped learners visualise [what was being asked]' (female, pre-interview, March). Five peer tutors discussed how they allowed learners to use different methods from the ones taught in class by the teacher to complete a task. According to 
Participant 6: 'I gave them more modern examples ... [ $I$ also] gave them some tricks to make it easier for them' (male, pre-interview, February). The finding is similar to both Milman and Wessmiller (2016) and Novak (2014) who claimed that relating mathematics in a tangible and specific way is important in getting learners' attention. From the finding, it can be deduced that the peer tutors believe that for the learners to increase their mathematics motivation it is important that they understood the mathematics in terms of their lived realities.

Three peer tutors discussed how they preferred working with worksheets with specific questions and methods to motivate learners to do mathematics. Participant 1 said that worksheets worked well because it meant that the learners 'actually had something to ask about' (female, post-interview, August). This finding concurs with Milman and Wessmiller (2016) suggesting that to get and keep learners' attention, teachers can use activities that involve numerous forms of collaboration.

Nine peer tutors addressed variation as the central way of capturing learners' attention. Variation is achieved by changing the way that the content is presented (Keller, 1987). Participant 8 found that it was important to try to 'make it more interesting, not just [your] standard teaching way of doing [the lesson]' (male, post-interview, October). Five peer tutors mentioned using a variety of teaching methods and styles to keep the learners' attention in mathematics. Participant 4 spoke about how he would see what the learners wanted to do: 'some [learners] preferred just to see it written down for them, or some [learners] preferred to do examples. They didn't just all learn in the same way' (male, postinterview, October). This finding corresponds with several researchers' findings that varying methods of engagement are important to improve learners' attention, which in turn affects their motivation (Izmirli \& Izmirli, 2015; Milman \& Wessmiller, 2016). This finding could indicate that the peer tutors were aware of the learners' needs and were conscious of getting and keeping their attention. These strategies provided varied and stimulating activities, which may have been different to what the learners had experienced in the past and could contribute to learners being more motivated to engage in the mathematics classroom.

Secondly, six peer tutors, thus more than half of participants, addressed stimulating inquiry, under the category of attention. These peer tutors stressed the importance of asking questions and engaging with the learners. Five of them specifically asked the learners questions. Participant 8 stated, 'I would ask them questions, so they can see for themselves where they are going wrong, so I [was continually] interacting with [the learners]' (male, post-interview, October). Three peer tutors addressing inquiry spoke about how they encouraged the learners to come prepared to ask questions, especially questions that the learners did not want to ask the teacher during class. This finding aligned with Hodges and Kim (2013) stating that mathematics teachers should encourage a sense of inquiry in order for learners to be more attentive. From this finding it is clear that the peer tutors believed they had the learners' attention and were engaged with them in such a way that the learners felt comfortable enough to engage openly and candidly with the peer tutors.

Lastly, maintaining learners' attention through participation under the category on attention was also addressed by six peer tutors, thus more than half of them. Most of these peer tutors indicated that they worked alongside the learners. Participant 3 interacted with the learners one on one until they had completed the question and remarked: 'I never just did something on my own and made them watch. I kept communicating with them to see if they were following' (male, post-interview, October). Encouraging learners to participate with the content is important in keeping the learners' attention. Winberg et al. (2014) also found that the learners' attitudes towards mathematics influence how they participate with the content, which can have a direct influence on their motivation to learn. By encouraging learners to participate not only with other learners, but also with the peer tutor and the content being presented, the peer tutors gave the impression that they were able to keep learners' attention on the mathematics being completed, which might have motivated learners to learn mathematics.

\section{Relevance}

The second category adapted from Keller's (1987) model of motivation is relevance. Keller (1987) noted that relevance is not simply the content being taught but can also be the way the content is taught. Under the category on relevance, three peer tutors felt that they did not explicitly address the relevance of mathematics with the learners, which could have led to some learners being unmotivated to learn mathematics. This acknowledgement may be interpreted that the rest of the peer tutors believed that the learners, who attended the tutorial sessions voluntarily, already knew that mathematics was relevant to their lives. Participant 8 said, 'I definitely think that they showed the initiative to come so that already shows that it is important to get good marks' (male, post-interview, October). This finding is similar to Chue and Nie (2017) asserting that learners need to be encouraged to make an effort, so that different learning approaches, such as tutorials, can affect achievement and motivation. By attending the tutorials, learners might have felt that they were able to receive help that would benefit them in the future. This finding could be interpreted that the learners who attended the tutorials were demonstrating a degree of self-regulation by acknowledging that attending the tutorials could help them achieve their goals, which might have addressed the problem of some learners being demotivated to learn mathematics.

The category on relevance comprises three aspects: relating to goals, matching interests and tying to experiences. None of the peer tutors discussed how they related the learners' mathematics goals to show the relevance of mathematics. Instead, they focused on how mathematics would affect 
the learners' future. As learners were not exposed to the usefulness of mathematics in real life, it could lead them to be unmotivated to participate in the mathematics classroom. However, four peer tutors, thus less than half of the participants, addressed the aspect of matching interest of mathematics by referring to the future usefulness of mathematics. Participant 7 said, ' $[I$ tried to $]$ make them understand how much they should understand maths right now, like the basics of it. [I] make them see how important it is in life' (female, post-interview, October). This finding is aligned with Oyserman et al. (2015) arguing that when people are motivated to complete a task (or in this case, attend a tutorial) they are envisioning its usefulness to their future, they are creating an image of who they would like to be one day, or what they are hoping to achieve. By introducing the relevance of mathematics in real life, the challenge of learners being unmotivated to participate in the mathematics classroom was addressed. Despite the previous, possibly negative, learning experiences a learner may have had with mathematics, they may still choose to engage in tutorials. When the peer tutors addressed and demonstrated the future relevance of what the learner could achieve, they could further enable the learner to envision what the future may hold, which may motivate learners to learn mathematics.

None of the peer tutors referred to linking mathematics to learners' experiences in order to demonstrate the relevance of mathematics and influence the motivation to pursue mathematics during the interviews. However, four peer tutors, fewer than half of the participants, addressed modelling. Participant 1 commented on how she believed that the learners could understand the importance of mathematics since there were peer tutors who apparently enjoyed the subject: '[tutoring has] got a lot of people who like maths in one room' (female, post-interview, August). Learners need mentors to show them the possibility to achieve (Moliner \& Alegre, 2020). Peer tutors are able to guide learners in becoming increasingly self-regulated (Heyd-Metzuyanim \& Graven, 2016; Hoops et al., 2016). This finding confirms what Moliner and Alegre (2020) stressed, namely that peer tutors are role models to learners. They can display what learners are able to achieve and they can assist learners with mathematics content. The peer tutors represent what they were able to achieve mathematically as they went through similar circumstances to the learners at an earlier stage.

\section{Confidence}

The category on confidence consists of three aspects, namely success expectations, success opportunities and personal responsibility. None of the peer tutors indicated that they explicitly laid out learning requirements to the learners. However, three peer tutors, thus few of the participants, spoke about organising questions in increasing levels of difficultly, thus creating success opportunities. Participant 10 said that he let the learners start with simple questions. '[I gave] them sums that would be easier for them to solve, so [the learners] don't [have as much to] write [otherwise the sums] look confusing and that is intimidating' (male, pre-interview,
February). This finding corresponds with LinnenbrinkGarcia, Patall and Pekrun (2016) who contended that when a task is perceived as too difficult, learners could be led to believe that they are failures, and this negatively influences their motivation. However, according to Pintrich (2003), when learners are presented with strategies that enable them to persevere with challenging tasks, and when they believe that they are prepared for the tasks, learners' motivation increases. Thus, this finding can be interpreted that when the peer tutors address learners' confidence to complete difficult tasks, the learners are more likely to persevere because of an increase in their level of motivation.

Only one peer tutor mentioned the relevance of expectations. Participant 1 claimed she felt that it was important that learners knew what was expected of them and that there was not only one way to get to the answer. This finding corresponds with Lazarides, Buchholz and Rubach (2018) stating that it is important that the teacher show interest in the subject and the work being completed to have the most impact on learners' interest. However, it could be deduced that most peer tutors did not address learners' expectations and, therefore, did not boost their self-confidence to learn mathematics, which led them to be still demotivated to participate in the mathematics classroom.

Seven peer tutors, thus many of the participants, focused on personal responsibility, which involves attribution and self-confidence. These seven peer tutors stated that they primarily assisted in improving learners' confidence by verbally attributing the learners' success to the effort that the learners were putting in. Participant 2 spoke about how important it was that she was patient when learners got an answer wrong. It was important for her that the learners knew they could do the work for themselves. She reflected, 'I think it's a big thing [for us] just being patient ... letting them know they can do it and letting them know that we are here for them' (female, pre-interview, March). Although not explicitly addressed, four peer tutors, thus less than half of the participants, implied that they helped learners' mathematics self-confidence by allowing learners to work more independently (Keller, 1987). Participant 7 said that she ensured that the learners knew she was there to assist but 'eventually they would just do it themselves' (female, postinterview, October). These peer tutors allowed learners to practise and repeat under low-risk conditions (Keller, 1987). Participant 8 stated that he would remain close to the learner but allow them to figure the sum out for themselves (male, post-interview, October). Two peer tutors, thus very few of the participants, believed that they helped learners' selfconfidence by creating a safe space where the learners knew they did not have to be perfect. Participant 9 said she encouraged the learners even when they made mistakes: 'It's okay, try again' (female, post-interview, October).

Similar to the above-mentioned findings, but with reference to teachers, Ryan and Deci (2000) noted that competency, autonomy and relatedness are vitally important in a learners' development with their community of learning. When 
learners are highly motivated it is often due to the teacher giving clear goals addressing what Keller (2000) referred to as 'success expectations'. When the teacher has provided tasks that are difficult, the teacher is providing the learner with what Keller referred to as success opportunities. When teachers give learners a sense of autonomy, it enhances their personal responsibility. From the findings, the same applies to peer tutors. Some peer tutors addressed the needs regarding learners' competency, autonomy and relatedness by motivating learners through boosting their confidence.

\section{Satisfaction}

Although the category on satisfaction involves intrinsic satisfaction, rewarding outcomes and fair treatment, the peer tutors mainly remarked on rewarding outcomes when discussing learners' satisfaction. Only two peer tutors, thus very few participants, mentioned intrinsic satisfaction. Natural consequences, in the ARCS model of motivation, is allowing learners to use the skills that they have acquired and to reinforce their intrinsic pride (Keller, 1987). Participant 9 explained that she tried to show the learners that they are able to get better marks if they focus on their mistakes more closely before attempting to correct them. She indicated: 'I told them, if you are getting like a $65 \%$ you can push for a $70 \%$, so let's try look at the small little things you are doing wrong' (female, post-interview, June). This finding concurs with Ryan and Deci (2000) alluding to intrinsic motivation being important, as it builds on the learners' inherent longing to learn. In mathematics, intrinsic motivation can often indicate how learners will achieve and what learners will be able to achieve in the long term (Singh, Granville, \& Dika, 2002). Some of the peer tutors recognised learners' inherent desire to learn and attempted to give them some personal strategies to enable the learners to take charge of their own learning and, by implication, futures. According to Keller (1987), addressing the learners' intrinsic satisfaction should help increase the learners' motivation.

Five peer tutors, thus half of the participants, referred to the aspect of rewarding outcomes. Two of these peer tutors specifically alluded to unexpected rewards (Keller, 2000). Unexpected rewards are compensations that encourage intrinsic motivation by rewarding boring tasks with unanticipated rewards (Keller, 1987). Participant 1 spoke about how she allowed the learners to complete the task on the teacher's whiteboard, which really encouraged the learners to do the exercises (female, post-interview, August). Participant 1 continued saying that she would have a competition (female, post-interview, August). Often learners' motivation to learn mathematics is linked to a reward or punishment. This finding aligns with Güvendir (2016) claiming that a reward is a form of extrinsic motivation, which is more easily addressed, if perceived as worthwhile, than intrinsic motivation. Thus, it can be deduced that the two peer tutors who responded on the aspect of rewarding outcomes are aware that creating a competition and using rewards motivate learners to work and they were satisfied with the work that they had executed. This finding demonstrates that small, seemingly insignificant, rewards do motivate learners to learn mathematics.

Lastly, five peer tutors mentioned positive outcomes, which can be given through verbal praise, giving personal attention to learners, informative feedback, as well as motivating feedback (Keller, 1987). These peer tutors spoke about how they addressed satisfaction by verbally praising the learners when they completed work. Participant 5 said he would inform learners of the difficulty of the work they had done. He would also praise them for doing it well. '[I] just told them to keep going: "That was really difficult you actually got it, well done"' (male, post-interview, October). According to Pintrich (2003), if learners believe that in the future there is a possibility that they will be able to overcome past failures, then they are more likely to persevere. From this finding, it could be deduced that peer tutors who encourage learners' satisfaction in their learning of mathematics may promote learners' motivation to persevere in mathematics, notwithstanding the challenges. The peer tutors empowered the learners to feel accomplished about the mathematics that they had done or were doing at that stage.

None of the peer tutors spoke about any negative influences, such as avoiding threats and comparisons. It is likely that the peer tutors understood that creating a negative experience for the learners would disadvantage the learners in learning mathematics. However, it is also likely that the peer tutors were themselves positively motivated to learn mathematics and therefore mirrored their motivation to their learners. In addition, none of the peer tutors mentioned frequent reinforcing of what learners had learnt. The peer tutors could possibly have addressed it indirectly or subconsciously during the tutorials, but it was not evident from the collected data.

\section{Discussion}

From the above results, some similarities were found pertaining to the peer tutors' views about their role in motivating Grade 8 and Grade 9 learners to learn mathematics in relation to the four categories of learner motivation, namely attention, relevance, confidence and satisfaction, adapted from Keller (1987). All 10 peer tutors understood their role to be a supporter to learners, which could be achieved through positively reinforcing what the learners had been taught in their mathematics lessons. The peer tutors also conceived their role to be flexible relative to how the learners learnt mathematics. The peer tutors discussed how they would attempt to improve learners' confidence by explaining mathematics work to the learners in ways that they could understand best. Furthermore, the peer tutors were open to explaining and giving learners' work that matched with the learners' interests. The peer tutors did not believe that they should simply assign work to the learners but were conscious of ensuring that the learners were able to complete the work that they were given without overwhelming the learners and causing them to give up. 
The main differences were about how the peer tutors believed that they would address the relevance of mathematics. Many of the peer tutors discussed exploring future careers in mathematics and doing research with the learners so that the learners could apply mathematics to real-world problems that interested them. However, they did not discuss that they related the relevance of mathematics to learners' personal, future plans.

Under the category of attention, it is apparent that the peer tutors were able to capture learners' attention mainly through giving concrete examples and through using methods dissimilar to those taught in the classroom. Capturing learners' attention was the predominant method that was noted to get learners' attention. The majority of the peer tutors addressed maintaining attention through participation. Getting learners' attention through using different methods of engagement was the most common method utilised by peer tutors. The findings indicate that peer tutors were able to get learners' attention through concreteness and variation. Peer tutors also believed learners' attention could be maintained by means of stimulating inquiry, as well as through participation. This finding is in agreement with Ryan and Deci (2000) claiming that when learners have a feeling of connectedness to the task that they are completing, their intrinsic motivation is developed. Winberg et al. (2014) also noted that when learners have a positive experience of learning and believe that they have connected to the community of learning, in this case mathematics, their intrinsic motivation is strengthened. This finding could indicate not only that the peer tutors prioritised participation in a community of learning, but also that learners' intrinsic mathematics motivation could have been developed or strengthened during the tutorials.

Under the category of relevance, it is evident that most of the peer tutors believed that their role was to demonstrate to learners the relevance of mathematics by matching learners' interests through demonstrating the future usefulness of mathematics and matching learners' needs. This finding is similar to Oyserman et al. (2015) discussing the need for motivation that encourages a person to achieve because of future prospects. Weiner (2010) found that when learners believe that there are future incentives and successes in the offing, they are motivated to complete work immediately to enable them to reach their future goals. From this finding, it is evident that peer tutors usually have a good understanding of working towards a goal that could make mathematics relevant. They also realise the importance of linking the learners' future interests with what they are currently working on in mathematics.

Under the category of confidence, the findings show that peer tutors understood their role to encourage learners to take personal responsibility for their work. They attributed their work to the learners' effort and to encouragement of learners to become increasingly self-confident in their mathematics abilities. This finding coincides with Cleary et al. (2017) arguing that when learners believe they can complete a task, often through preparedness, their motivation to continue in the future and to interact with the community of learning is positively impacted.

Finally, under the category of satisfaction, the peer tutors demonstrated that their role was predominantly to encourage learners to participate in the content, as well as with another person. This finding corresponds with Hodges and Kim (2013) stating that when learners are encouraged to participate with the content, it helps maintain their attention. However, none of the 10 peer tutors addressed fair treatment. According to Keller (2000, p. 4), fair treatment can be done by supporting learners in securing a positive attitude about their successes.

\section{Conclusion}

Low mathematics performance not only influences learners' progression in the subject but also affects how the world views a country's ability to perform in the international domain. A strategy to enhance learners' performance in mathematics is to motivate them to learn mathematics. When learners are motivated to learn mathematics, they are more likely to participate in the mathematics classroom. Peer tutoring is one strategy that can assist in motivating learners. The authors of this article argue that if teachers are cognisant of and act on the role peer tutors play in motivating learners to learn mathematics, performance in the subject can improve. Thus, this article reported on Grade 12 peer tutors' views on their role in motivating Grade 8 and Grade 9 learners to learn mathematics in relation to the four categories of learner motivation, namely attention, relevance, confidence and satisfaction, adapted from Keller (1987).

The findings in this article showed that peer tutors indeed understood their role to motivate Grade 8 and Grade 9 learners to learn mathematics. They knew that they needed to, and were able to, collaborate with the Grade 8 and Grade 9 learners to provide support in the learning of mathematics that was relevant and engaging. The peer tutors' views on their role to motivate Grade 8 and Grade 9 learners to learn mathematics was to be (1) capturers of learners' attention, (2) stimulators of learners' mathematics inquiry, (3) maintainers of learners' attention, (4) matchers of learners' interests, (5) models of good mathematicians, (6) promoters of learners' self-confidence and (7) encouragers addressing learners' satisfaction in learning mathematics. These findings support the argument of the authors, namely that now that teachers are cognisant about the role peer tutors play in motivating learners to learn mathematics, they can develop peer tutors further in their roles and utilise them in this regard, which in turn can improve performance in mathematics.

This article contributes to the understanding of peer tutors' role as motivators regarding support to Grade 8 and Grade 9 learners in their learning of mathematics, which can be valuable for future intervention programmes utilising peer tutors at school level. This article also adds to the research on 
an adapted use of Keller's (1987) ARCS model of motivation as a framework, specifically in motivating learners to learn mathematics, which is a novel way of bringing new perspectives on motivation in mathematics at secondary school level. An implication in developing peer tutors in their role to motivate learners to learn mathematics is to strengthen their skills regarding capturing learners' attention, showing learners the relevance of mathematics, increasing learners' confidence and ensuring that learners are satisfied by encouraging perseverance.

A limitation of this article was that data were collected and analysed in a short period of only nine months. More data collection instruments could have ensured triangulation of the data. For example, observations on how peer tutors enact their role while assisting learners could have ensured the accuracy of their interpretation of their role. Weekly reflection reports between the pre- and post-interviews could have cross-checked the evolution of peer tutors' views on their role in motivating learners to learn mathematics. Quantitative data could have established peer tutors' levels of executing their role as motivators, but might also have examined the attitudes of both peer tutors and learners. The sample of 10 peer tutors at one particular school was not representative of all peer tutors in South Africa. Thus, the findings on the role peer tutors play in motivating learners is of importance to similar contexts utilising a peer-tutoring programme specifically to address learning in mathematics. However, the findings are not necessarily transferable to other school subjects and cannot be generalised to different contexts. Although an adapted version of Keller's (1987) ARCS model of motivation was applicable in the South African context to analyse peer tutors' role as motivators in the learning of mathematics, it narrowed the role of peer tutors to only one aspect, namely motivation. More research is needed on other roles of peer tutors, such as being a critical friend, modelling appropriate behaviours, focusing on learners' needs, supporting learners to complete tasks, preparing learning materials for tutoring sessions as directed by the teacher and monitoring progress toward academic goals. Although peer tutors cannot substitute the content and teaching expertise of the mathematics teacher, their roles are important because they facilitate a learning climate that is friendly, but conversely rigorous. They extend in a supporting capacity on the learning that occurs in the mathematics classroom, which may assist learners in their progress in the subject.

For future research in the area of motivation in mathematics, this research may be extended to a longitudinal study by focusing not only on peer tutors' views on their role to motivate learners in their learning of mathematics, but also on how to develop peer tutors in various roles. A larger, more diverse sample emphasising different school demographics is also suggested. A further recommendation is a study investigating the affordances of a peer-tutoring intervention for learners in their learning of mathematics, because explaining a mathematics concept to another extends a learner's own understanding of the subject. Such an intervention could also deepen learners' knowledge of mathematics by allowing them to practise challenging concepts and, in turn, develop their problem-solving skills.

In conclusion, peer tutors' understanding of their role as motivators aligns with research on an adapted use of Keller's (1987) ARCS model of motivation and this model can be a useful lens to help address learner motivation. From the findings, the peer tutors were able to motivate learners and believed that learners' motivation increased through the tutorials. For this reason, peer tutoring can be seen as a useful intervention strategy to help address learner motivation. Going forward, the findings from this research can be expanded to further address motivation in mathematics to help improve the pass rates of South African learners.

\section{Acknowledgements}

Gratitude is expressed to the participants at the school in which this study took place. Also, many thanks to colleagues, friends and family for their encouragement and advice.

\section{Competing interests}

The authors have declared that no competing interest exists.

\section{Authors' contributions}

Since this article is based on A.K.R.'s master study and E.D.S. was the supervisor of the study in Mathematics Education, A.K.R. collected the data, while E.D.S. provided academic inputs and technical editing to the manuscript. Both authors contributed in terms of the conceptualising and writing the manuscript.

\section{Funding information}

This research received no specific grant from any funding agency in the public, commercial, or not-for-profit sectors.

\section{Data availability statement}

Data sharing is not applicable to this article as no new data were created or analysed in this study.

\section{Disclaimer}

The views and opinions expressed in this article are those of the authors and do not necessarily reflect the official policy or position of any affiliated agency of the authors.

\section{References}

Alegre, F., Moliner, L., Maroto, A., \& Lorenzo-Valentin, G. (2019). Peer tutoring and mathematics in secondary education: Literature review, effect sizes, moderators, and implications for practice. Heliyon, 5(9), e02491. https://doi.org/10.1016/j. heliyon.2019.e02491 
Alegre, F., Moliner, L., Maroto, A., \& Lorenzo-Valentin, G. (2020). Academic achievement and peer tutoring in mathematics: A comparison between primary and secondary education. SAGE Open, 10(2), 1-9. https://doi.org/10.1177/ and secondary educat

Arroyo, I., Woolf, B.P., Burelson, W., Muldner, K., Rai, D., \& Tai, M. (2014). A multimedia adaptive tutoring system for mathematics that addresses cognition, metacognition and affect. International Journal of Artificial Intelligence in Education, 24(4) 387-426. https://doi.org/10.1007/s40593-014-0023-y

Bartelet, D., Ghysels, J., Groot, W., Haelermans, C., \& Maassen Van den Brink, H. (2016). The differential effect of basic mathematics skills homework via a webbased intelligent tutoring system across achievement subgroups and mathematics domains: A randomized field experiment. Journal of Educational Psychology, 108(1), 1-20. https://doi.org/10.1037/edu0000051

Braun, V., \& Clarke, V. (2006). Using thematic analysis in psychology. Qualitative Research in Psychology, 3(2), 77-101. http://dx.doi.org/10.1191/1478088706qp063oa

Chue, K.L., \& Nie, Y. (2017). Study orchestrations and motivational differences in a mathematical context. Learning and Individual Differences, 57(June), 77-84. https://doi.org/10.1016/j.lindif.2017.06.002

Clarence, S. (2018). Towards inclusive, participatory peer tutor development in higher education Sherran Clarence. Critical Studies in Teaching and Learning, 6(1), 58-74. https://doi.org/10.14426/cristal.v6i1.141

Cleary, T., Velardi, B., \& Schnaidman, B. (2017). Effects of the self-regulation empwerment program on middle school students' strategic skills, self-efficacy, and mathematics achievement. Journal of School Psychology, 64(April), 28-42. https://doi.org/10.1016/j.jsp.2017.04.004

Creswell, J.W. (2013). Qualitative inquiry and research design (3rd edn.). Los Angeles, CA: Sage.

De Backer, L., Van Keer, H., \& Valcke, M. (2015). Exploring evolutions in reciprocal peer tutoring groups' socially shared metacognitive regulation and identifying its metacognitive correlates. Learning and Instruction, 38, 63-78. https://doi. metacognitive correlates. Learning and
org/10.1016/j.learninstruc.2015.04.001

Galbraith, J., \& Winterbottom, M. (2011). Peer-tutoring: What's in it for the tutor? Educational Studies, 37(3), 321-332. https://doi.org/10.1080/03055698.2010.50 6330

Gardner, R.C. (1985). Social psychology and second language learning: The role of attitudes and motivation. London: Arnold.

George, A., \& Adu, E.O. (2018). Motivation and attitude of grade nine learners towards mathematics in King Williams Town Education District, South Africa. Ghan Journal of Development Studies, 15(1), 135-150. http://doi.org/10.4314/gids. v15i1.7

Greene, I., Mc Tiernan, A., \& Hollow, J. (2018). Cross-age peer tutoring and fluencybased instruction to achieve fluency with mathematics computation skills: A randomized controlled trial. Journal of Behavioral Education, 27, 145-171. https://doi.org/10.1007/s10864-018-9291-1

Grills, S. (2017). Incorporating peer mentor tutorials into a success course for diverse students. Journal of the Australia and New Zealand Student Services Association 49(49), 100-109. https://doi.org/10.1002/ss.20219

Grobler, B., Moloi, C., \& Thakhordas, S. (2017). Teachers' perceptions of the utilisation of emotional intelligence by their school principals to manage mandated curriculum change processes. Educational Management Administration and Leadership, 45(2), 336-355. https://doi.org/10.1177/1741143215608197

Güvendir, M.T. (2016). Students' extrinsic and intrinsic motivation level and its relationship with their mathematics achievement. International Journal for Mathematics Teaching and Learning, 17(1), 1-21.

Goldin, G.A., Hannula, M.S., Heyd-Metzuyanim, E., Kaisila, R., Lutovac, S., Di Martino, P., Morselli, F., ..., \& Zhang, Q. (2016). Attitudes, beliefs, motivation and identity in mathematics education. Cham: Springer International. https://doi. mathematics education. Cham:
org/10.1007/978-3-319-32811-9_1

Heckhausen, H. (2018). Historical trends in motivation research. In J. Heckhausen \& H. Heckhausen (Eds.), Motivation and action (3rd edn., pp. 1-909). Cham: Springer. https://doi.org/10.1007/978-3-319-65094-4

Hernandez-Martinez, P., \& Vos, P. (2018). 'Why do I have to learn this?' A case study on students' experiences of the relevance of mathematical modelling activities. ZDM, 5O(1), 247-257. https://doi.org/10.1007/s11858-017-0904-2

Heyd-Metzuyanim, E., \& Graven, M. (2016). Between people-pleasing and mathematizing: South African learners' struggle for numeracy. Educational Studies

odges, C.B., \& Kim, C. (2013). Improving college students' attitudes toward mathemathics. TechTrends, 57(4), 59-66. https://doi.org/10.1007/s11528-0130679-4

Hoops, L.D., Yu, S.L., Wang, Q., \& Hollyer, V.L. (2016). Investigating postsecondary selfregulated learning instructional practices: The development of the self-regulate learning observation protocol. International Journal of Teaching and Learning in Higher Education, 28(1), 75-93.

Huang, X., Craig, S.D., Xie, J., Graesser, A., \& Hu, X. (2016). Intelligent tutoring systems work as a math gap reducer in 6th grade after-school program. Learning and Individual Differences, 47, 258-265. https://doi.org/10.1016/j.lindif.2016.01.012

Izmirli, S., \& Izmirli, O.S. (2015). Factors motivating preservice teachers for online learning within the context of ARCS motivation model. Turkish Online Journal of Distance Education, 16(2), 56-68. https://doi.org/10.17718/tojde.26620

Karakis, H., Karamete, A., \& Okcu, A. (2016). The effects of a computer-assisted teaching material, designed according to the ASSURE instructional design and the ARCS model of motivation, on students' achievement levels in a mathematics lesson and their resulting attitudes. European Journal of Contemporary Education 15(1), 105-113. https://doi.org/10.13187/ejced.2016.15.105
Keller, A. (2017). How to gauge the relevance of codes in qualitative data analysis? A technique based on information retrieval. In J.M. Leimeister \& W. Brenner (Eds.), Proceedings of the 13th International Conference on Wirtschaftsinformatik (pp. 1096-1110). St Gallen: Institute of Information Management.

Keller. J.M. (1987). Development and use of the ARCS model of instructional design Journal of Instructional Development, 10(3), 2-10. https://doi.org/10.1007/ BF02905780

Keller. J.M. (2000). How to integrate learner motivation planning into lesson planning The ARCS model approach. Paper presented at VII Semenario, Santiago, Cuba, 19-21 October.

Kim, C., Park, S.W., Cozart, J., \& Lee, H. (2015). From motivation to engagement: The role of effort regulation of virtual high school students in mathematics courses. Educational Technology \& Society, 18(4), 261-272.

Kivunja, C., \& Kuyini, A.B. (2017). Understanding and applying research paradigms in educational contexts. International Journal of Higher Education, 6(5), 26-41. https://doi.org/10.5430/ijhe.v6n5p26

Kroeger, S.D., \& Kouche, B. (2006). Using peer-assisted learning strategies to increase response to intervention in inclusive middle math settings. Teaching Exceptional Children, 38(5), 6-13. https://doi.org/10.1177/004005990603800501

Layton, D., \& McKenna, S. (2016). Partnerships and parents - Relationships in tutorial programmes. Higher Education Research and Development, 35(2), 296-308. https://doi.org/10.1080/07294360.2015.1087471

Lazarides, R., Buchholz, J., \& Rubach, C. (2018). Teacher enthusiasm and self-efficacy, student-perceived mastery goal orientation, and student motivation in mathematics classrooms. Teaching and Teacher Education, 69, 1-10. https://doi. org/10.1016/j.tate.2017.08.017

Linnenbrink-Garcia, L., Patall, E.A., \& Pekrun, R. (2016). Adaptive motivation and emotion in education. Policy Insights from the Behavioral and Brain Sciences, 3(2) 228-236. https://doi.org/10.1177/2372732216644450

Lutovac, S., \& Kaasila, R. (2014). Pre-service teachers' future-oriented mathematical identity work. Educational Studies in Mathematics, 85(1), 129-142. https://doi. org/10.1007/s10649-013-9500-8.

Milman, N.B., \& Wessmiller, J. (2016). Motivating the online learner using Keller's ARCS Model. Distance Learning, 13(2), 67-71.

Moliner, L., \& Alegre, F. (2020). Attitudes, beliefs and knowledge of mathematics teachers regarding peer tutoring. European Journal of Teacher Education, 43(4), 1-20. https://doi.org/10.1080/02619768.2020.1803271

Mullis, I.V.S., Martin, M.O., Foy, P., \& Hooper, M. (2016). TIMSS 2015 international results in mathematics. Chestnut Hill, MA: TIMSS \& PIRLS International Study Center, Boston College. http://timssandpirls.bc.edu/timss2015/internationalresults

Nawaz, A., \& Rehman, Z.U. (2017). Strategy of peer tutoring and students success in mathematics: An analysis. Journal of Research and Reflections in Education, 11(1), 15-30.

Novak, E. (2014). Toward a mathematical model of motivation, volition, and performance. Computers and Education, 74, 73-80. https://doi.org/10.1016/j. compedu.2014.01.009

Ntow, F.D., \& Adler, J. (2019). Identity resources and mathematics teaching identity: An exploratory study. ZDM, 51, 419-432. https://doi.org/10.1007/s11858-019-01025-z

Oswald, M., \& Rabie, E. (2016). Rethinking gifted education in South Africa: The voices of gifted grade 11 students. Gifted Education International, 33(3), 1-13. https:// doi.org/10.1177/0261429416642285

Oyserman, D., Destin, M., \& Novin, S. (2015). The context-sensitive future self: Possible selves motivate in context, not otherwise. Self and Identity, 14(2), 173-188. https://doi.org/10.1080/15298868.2014.965733

Pintrich, P.R. (2003). A motivational science perspective on the role of student motivation in learning and teaching contexts. Journal of Educational Psychology, 95(4), 667-686. https://doi.org/10.1037/0022-0663.95.4.667

Rheinburg, F., \& Engeser, S. (2018). Intrinsic motivation and flow. In J. Heckhausen \& H. Heckhausen (Eds.), Motivation and action (3rd edn.), pp. 1-909, Cham: Springer. https://doi.org/10.1007/978-3-319-65094-4_14

Roberts, A.K. (2019). Grade 12 peer tutors' conceptions of their role as motivators for Grades 8 and 9 mathematics learners. Unpublished master's thesis, University of Johannesburg, Johannesburg. Retrieved from http://hdl.handle.net/10210/411883

Rule, P., \& John, V. (2011). Your guide to case study research. Pretoria: Van Schaik Publishers.

Ryan, R.M., \& Deci, E.L. (2000). Self-determination theory and the facilitation of intrinsic motivation, social development, and well-being. American Psychologist, 55(1), 68-78. https://doi.org/10.1037/0003-066X.55.1.68

Schukajlow, S., Rakoczy, K., \& Pekrun, R. (2017). Emotions and motivation in mathematics education: Theoretical considerations and empirical contributions. ZDM Mathematics Education, 49(3), 307-322. https://doi.org/10.1007/s11858017-0864-6

Schwab, K. (2015). The global competitiveness report 2015-2016. Geneva: World Economic Forum. Retrieved from http://www3.weforum.org/docs/gcr/2015 2016/Global_Competitiveness_Report_2015-2016.pdf

Singh, K., Granville, M., \& Dika, S. (2002). Mathematics and science achievement: Effects of motivation, interest, and academic engagement. Journal of Educational Research, 95(6), 323-332. https://doi.org/10.1080/00220670209596607

The Oxford advanced learner's dictionary. (2010). Oxford: Oxford University Press. Retrieved from https://www.oxfordlearnersdictionaries.com/definition/ english/ 
Topping, K.J., Campbell, J., Douglas, W., \& Smith, A. (2003). Cross-age peer tutoring in mathematics with seven- and 11-year-olds: Influence on mathematical vocabulary, strategic dialogue and self-concept. Educational Research, 45(3), 287-308. https://doi.org/10.1080/0013188032000137274

Tsanwani, A., Harding, A., Engelbrect, J., \& Maree, K. (2014). Perceptions of teachers and learners about factors that facilitate learners' performance in mathematics in South Africa. African Journal of Research in Mathematics, Science and Technology, 18(1), 40-51. https://doi.org/10.1080/10288457.2014.884262

Weiner, B. (2010). The development of an attribution-based theory of motivation A history of ideas. Educational Psychologist, 45(1), 28-36. https://doi. org/10.1080/00461520903433596
Wilkins, J.L.M., \& Ma, X. (2003). Modeling change in student attitude toward and beliefs about mathematics. Journal of Educational Research, 97(1), 52-63. https://doi.org/10.1080/00220670309596628

Winberg, T.M., Hellgren, J.M., \& Palm, T. (2014). Stimulating positive emotional experiences in mathematics learning: Influence of situational and personal factors. European Journal of Psychology of Education, 29(4), 673-691. https://doi. org/10.1007/s10212-014-0220-y

Yu, R., \& Singh, K (2016). Teacher support, instructional practices, student motivation, and mathematics achievement in high school. The Journal of Educational Research, 111(1), 1-14. https://doi.org/10.1080/00220671.2016.1204260 